\title{
Anti-CD79a Antibody
}

National Cancer Institute

\section{Source}

National Cancer Institute. Anti-CD79a Antibody. NCI Thesaurus. Code C118799.

Any antibody that recognizes B-cell antigen receptor complex-associated protein alpha chain protein. 